\title{
A medical perspective of the practice of semi-permanent makeup in South Korea
}

\author{
Chang Won Koh, MD, $\mathrm{PhD}^{1}$ (iD, Kyoungjin (Safi) Kang, MD, $\mathrm{PhD}^{2}$ (i) \\ 'Department of Public Health Service, Seoul National University Bundang Hospital, Seongnam, Rep. of Korea \\ ${ }^{2}$ Seoul Face 21 Clinic, Seoul, Rep. of Korea
}

\begin{abstract}
Background: Despite existing problems with infection control and healthcare regulations associated with semi-permanent makeup, its practice by non-medical personnel at non-healthcare institutions continues to pose fatal risks to the safety of the community. Objective: The aim of this study is to seek for improvement measures on the Korean legal system regarding the practice of semipermanent makeup by investigating current conditions of the procedure and materials used, reviewing past clinical reports of complications associated with tattooing, and assessing domestic and foreign laws and regulations of semi-permanent makeup.

Methods: Both domestic and foreign studies and publications on the regulatory system with regards to semi-permanent makeup, in addition to clinical cases of complications associated with semi-permanent makeup, were reviewed.

Results: Tattoo procedures in South Korea and Japan are strictly restricted to medical personnel, while other countries also regulate the practice of tattoo with a license-based system rather than a qualification-based system such that non-medical personnel can perform under medical supervision. The duration and placement of pigments in the dermis of the skin and its possible complications associated with the procedure have been confirmed; short-term side effects are bleeding, infection, allergic reaction and Koebner phenomenon, and long-term side effects are foreign body reaction, granuloma. Local infections caused from tattoos include warts, herpes simplex; systemic infections include hepatitis B and C, HIV; toxic immune reactions include erythema multiforme, vasculitis, granuloma. To address these issues, examination of patient history for potential indications, established protocol for medical waste management, and stringent regulations for hygiene product management are necessary.

Conclusion: Measures such as the establishment of a license-issuance system that is inclusive of education and training on the proper practice of semi-permanent makeup and stricter management of tattoo-related materials and devices should be enforced in order to ensure infection control and the safety of the public health.
\end{abstract}

Key Words: healthcare regulation; infections; license-issuance system; safety of public health; semi-permanent makeup; tattooing

\section{Introduction}

The tattoo vehicle is composed of inks, dyes, and pigments that are injected into the designated area of the skin, making permanent or temporary changes to the normal skin pigmentation. Tattoos can be classified into five types: traumatic, sub- cultural connotations, identification, cosmetic, functional, and medical [1]. The longevity of the tattoo is determined by the placement of the pigments: ink deposited into the dermis has permanent results, while a deposit into the epidermis is semipermanent, as it naturally fades [2].

Semi-permanent makeup is mainly used for cosmetic pur-

Received May 24, 2021; Revised May 31, 2021; Accepted June 1, 2021

Corresponding author: Chang Won Koh

E-mail:kcwbnl@gmail.com

This is an Open Access article distributed under the terms of the Creative Commons Attribution Non-Commercial License (http://creativecommons.org/licenses/by-nc/4.0), which permits unrestricted non-commercial use, distribution, and reproduction in any medium, provided the original work is properly cited.

Copyright $@ 2021$ Korean Society of Korean Cosmetic Surgery and Medicine (KSKCS \& KCCS). 
Table 1. Comparison of tattoo and micropigmentation

\begin{tabular}{lll}
\hline \multicolumn{1}{c}{ Variable } & \multicolumn{1}{c}{ Tattoo } & Micropigmentation [8] \\
\hline Duration & Life long & Several years \\
Treatment area & $\begin{array}{c}\text { Anywhere including } \\
\text { body }\end{array}$ & Mainly face \\
Type of needle & $1-2 \mathrm{~mm}$ size & $\begin{array}{c}\text { Tattoo machine 1-9 } \\
\text { point }\end{array}$ \\
Target skin layer & Dermis & Dermis \\
\hline
\end{tabular}

poses: to improve the shape, size, or asymmetry of the eyebrows, eyelashes, and lips. Female athletes (who engage in rigorous activities that lead to excessive perspiration), seniors with vision problems, or patients who lost their eyebrows due to chemotherapy are just a few examples of individuals who use cosmetic tattooing in lieu of daily makeup application.

For others, tattooing is adjunct to medical reconstructive procedures. This is considered micropigmentation, meaning the process of tattooing for medical purposes (Table 1) [3]. Micropigmentation includes infusing pigmentation into the nipples and areolas of patients after breast cancer surgery, coloring transplanted skin post-irradiation therapy, and correcting cleft lip deformities or camouflaging the appearance of scars.

Semi-permanent makeup requires 12 treatments, depending on the individual's skin characteristics, patient's lifestyle, and type of pigment and technique employed. Ink injected into the epidermis naturally fades with time due to keratinization of the skin. Still, semi-permanent makeup lasts between 6 months and 3 years [4].

It is estimated that the tattoo market in Korea is worth 2 trillion won per year, with approximately 10 million individuals getting semi-permanent tattoos and 200,000 to 300,000 tattoo artists practicing $[5,6]$. Despite the prevalence of semi-permanent makeup, there are reports of legal malpractice (based on the Supreme Court of Korea Decision 2017 Da 19422 Decided June 19, 2018) and procedural complications [7]. Indeed, the indiscriminate application of semi-permanent makeup, without carefully adopting appropriate hygiene control measures, poses a threat to public health and safety.

Thus, this study aims to provide insight into improving community health by addressing procedural standards, potential adverse outcomes, and the current legal regulations of semipermanent makeup based on past research and literature.

\section{Materials and methods}

\section{Procedure}

For semi-permanent makeup, pigments are injected into the skin at various depths, depending on the target area. It is typically embedded 1-2 mm below the skin's surface. If injected at a depth of $1 \mathrm{~mm}$ or less, pigments tend to fade within two weeks as the resultant scabs heal. If injected at a depth of $2 \mathrm{~mm}$ or more, however, it lasts approximately 2 to 3 months and is eventually lightened by the influence of macrophages [8].

Pigments typically begin to fade from week 1 post-procedure, and continue to lighten until week 6 . They are minimally visible after 2 to 3 years [9]. Thus, the 2-3 year duration of semi-permanent makeup is comparatively longer than the 4 to 6 weeks it takes for the skin to keratinize. If a secondary revision procedure is performed within 2 weeks of the primary procedure, signs of inflammation, such as edema, pain, and erythema, may develop. Symptoms of inflammation and bleeding are usually unaccompanied when artists operate only on the epidermal layer.

Semi-permanent makeup is applied using a machine or pen. In the former technique, the rotary rapidly moves an attached needle up and down, infusing the pigment into the skin surface. For its part, the pen method requires one to operate the needle piece manually [10]. In the medical field, micropigmentation involves a eutectic mixture of local anesthetic (lidocaineprilocaine). It is topically applied to the designated area for approximately 30 minutes. Subsequently, the skin is disinfected with $70 \%$ isopropyl alcohol before the operation. The treatment device is set to 120 strokes per seconds. The treatment site dictates the size of the needle (1-9 point) selected, along with the depth of the dermis layers the pigments are introduced to. Following the procedure, antibiotic ointment is applied to the site daily [11].

\section{Tattoo ink}

It is first necessary to validate proper sterilization and sanitary guidelines, and verify registration for the tattoo before its use. The product should meet the material safety data sheet requirements.

In Europe, the European Council Resolution ResAP (2008) implements and manages tattoo ink regulation. In the United States, tattoo inks are classified as color additives, which the Food and Drug Administration has not approved for use in tattoo practices [12]. It is crucial that safety standards for inks be critically evaluated and consistently applied in both the United States and South Korea.

Since January 1, 2020, tattoo inks have been subjected to the Cleansing and Hygiene Product Control Act and are regulated by the Ministry of Food and Drug Safety in South Korea. Hence, 
manufacturers, importers, and distributors must complete compulsory training, meet the standards of the Good Manufacturing Practice facility, and file reports with the Ministry of Food and Drug Safety. In addition, only products approved by the regional office of food and drug safety can be distributed and sold $[3,6]$.

\section{Law and regulation}

\section{Korean law}

South Korean law views tattoos and semi-permanent makeup as medical procedures practiced by non-medical personnel and prohibits them. According to Article 25 of Section 3 of Medical Practitioner's Law, such activities may only be performed by persons with medical licenses. Moreover, even among medical personnel, they may only be carried out by those with full qualifications. Tattoo procedures performed by non-medical personnel and even non-licensed medical personnel are now considered a violation of Article 27 of the Medical Service Act. Pursuant to Article 87 of the Medical Service Act, violators may be punished by imprisonment for a term of up to five years, or fined. In addition to the Medical Service Act, medical practices performed by non-medical personnel for the purpose of profit will be subjected to legal and penal measures-per Article 5 of the Act on Special Measures for the Control of Public Health Crimes.

In a precedent case, a makeup practitioner was found guilty for accidentally injecting the pigment into the dermis and placing the client at risk for disease transmission by using tattoo needles (Supreme Court of Korea Decision 1991 Da 3219 Decided May 22, 1992). This case fell under the legal concept of medical practice, which covers any procedure involving the prevention or treatment of diseases that require physical or clinical examination, prescription, treatment, or surgical procedure by qualified medical personnel. The judgement found that the risk of infection (and other health problems) resulting from illegal procedural conduct by non-medical personnel in itself is sufficient to be punished for violation-even if the patient experiences no symptoms (Supreme Court of Korea Decision 2017 Da 19422 Decided June 19, 2018).

\section{Foreign law}

The U.S. Society of Permanent Cosmetic Professionals was established in 1990 to promote professional standards for the application of permanent cosmetics. On the local level, the State of New York, for instance, issues an official license by The
City of New York Department of Health Tattoo Artist to ensure that practitioners are formally trained and educated on proper health practices. Practitioners must also use devices and inks certified by the U.S. Food and Drug Administration [13].

Strict regulations are enforced in several states. In Connecticut, qualifications for tattoo and semi-permanent makeup artists are restricted to medical personnel, such as medical physicians, nurses, and medical assistants or licensed tattooists [14]. Healthcare professionals or technicians other than medical physicians may perform procedures only under the supervision of physicians, and the physician in charge is responsible for annually inspecting the facility's hygiene conditions equipment, as well as records of the practitioner's qualifications [15]. The practitioner should be notified in advance about specific indications that require professional medical attention. In South Carolina, tattoos are permitted in cases deemed necessary by the licensed medical physician performing the cosmetic or reconstructive procedures. Oklahoma classifies tattoos as medical micropigmentation and restricts the practice to medical physicians, dentists, nurses, and technicians with micropigmentation licenses. Non-health professionals with licenses may only practice under the supervision of a medical physician. Finally, Hawaii allows facial tattoos to be performed by a licensed physician or tattoo specialists under the supervision of a physician [16].

In France, regulatory policies mandate that the individual getting tattooed is aware of the related hygiene standards, make provisions for manufacturing, packaging, and distribution, and require training for practitioners giving tattoos or piercings. Moreover, tattoo equipment is monitored at the national level. Advanced training, including a comprehensive curriculum on the regulations of dyes and tools used in the procedure, skin anatomy, public hygiene, infection, disinfection, and sterilization must be completed for the issuance of a license. Most countries have internalized the license-to-practice system instead of a competency-based system. A license is issued upon completion of a rigorous training course and the passing of the examination. Providing information on the hygiene and sanitary standards of the procedure and postoperative management to customers not increases awareness of infection control-it encourages safe practice. Indeed, clients can check whether the practitioner adheres to the safety regulations [17].

Japan also has strict regulatory policies for tattoos and semipermanent makeup. These procedures are classified as medical practices. Under Article 7 of the Medical Practitioners' Act (enforced on November 8, 2011), they can only be performed by medical physicians. Pursuant to Section 6 of Article 31 of 
the Medical Practitioners' Act, violators may be punished by imprisonment for a term of up to two years or fined up to 20,000 yen. Hokkaido, Japan's second largest island, implemented an ordinance for the protection of juveniles that restricts minors from getting tattooed [18].

\section{Results}

\section{Semi-permanent makeup complications}

Prior to the procedure, skin characteristics, medical history, and/or existing conditions must be thoroughly examined. The procedure should be avoided by individuals with a history of Koebner phenomenon (e.g., psoriasis, lichen planus, or vitiligo [19]), warts, molluscum contagiosum, herpes simplex, keloid, dye allergies, or the possibility of pregnancy [20]. In the case of herpes simplex, micropigmentation of the infected area may cause symptoms to recur within 2 to 3 days of the procedure. Medications such as isotretinoin can increase the risk of scarring, and anticoagulants may interfere with the healing process. Caution is especially needed for individuals taking blood thinners or with bleeding disorders. Other complications, such as pain, edema, bleeding, infection, and dye allergy may occur postoperatively. Regarding long-term side effects, foreign body reactions or granulomas may occur, as pigments are foreign substances, and incidents of basal cell carcinoma or malignant melanoma have been reported [21].

Systemic infectious complications from semi-permanent makeup include hepatitis B and C, HIV, syphilis, and tuberculosis. Immune response or toxic reactions may lead to the development of erythema multiforme, vasculitis, granuloma, and sarcoidosis. Localized skin infections such as warts, herpes simplex, molluscum contagiosum, erysipelas, and cellulitis have been reported [22,23]. However, existing studies that used magnetic resonance imaging in their analysis indicate that the possibility of such abnormalities is low [24].

Regarding infection control, the needles and gauze used in the procedure are exposed to bodily fluids and are classified as clinical waste. They must be securely sealed in a designated healthcare waste bag for disposal at licensed disposal facilities. It is difficult to dispose off clinical waste generated beyond medical institutions legally.

\section{Cases of adverse side effects in foreign countries}

History proves that negligence or misconduct in during the tattooing process can wreak havoc on public health. In the 1950s [25], for instance, a mass outbreak of hepatitis B in New
York City led to the closing of tattoo parlors. Similarly, in 1982, eight American soldiers were confirmed to have contracted hepatitis B during tattoo procedures in Amsterdam. Research on the transmissibility of hepatitis B ultimately prompted the establishment of regulations for infection prevention in tattoo studios in 1987 [16]. A meta-analysis of 163 published studies to evaluate the relationship between hepatitis $\mathrm{C}$ and tattooing demonstrated a higher occurrence rate and relative risk of hepatitis $\mathrm{C}$ in individuals with tattoos and a correlation of increased likelihood of contraction associated with the size of the tattoo. This study also indicates that tattooing can be a mode of human immunodeficiency virus transmission [22]. Moreover, there has been an incident of human papilloma virus transmission during semi-permanent makeup [26], while Mycobacterium abscessus and fungus coinfection took place at another makeup tattoo parlor [27].

\section{Cases of adverse side effects in South Korea}

There have been 11 confirmed cases of herpes simplex, 9 cases of contact dermatitis, 1 case of secondary bacterial infection, 1 case of scarring, and 1 case of ink misplacement in South Korea [28]. A 46-year-old female patient who received semi-permanent makeup on her lips reportedly showed signs of hepatomegaly, high fever, vomiting, and general weakness associated

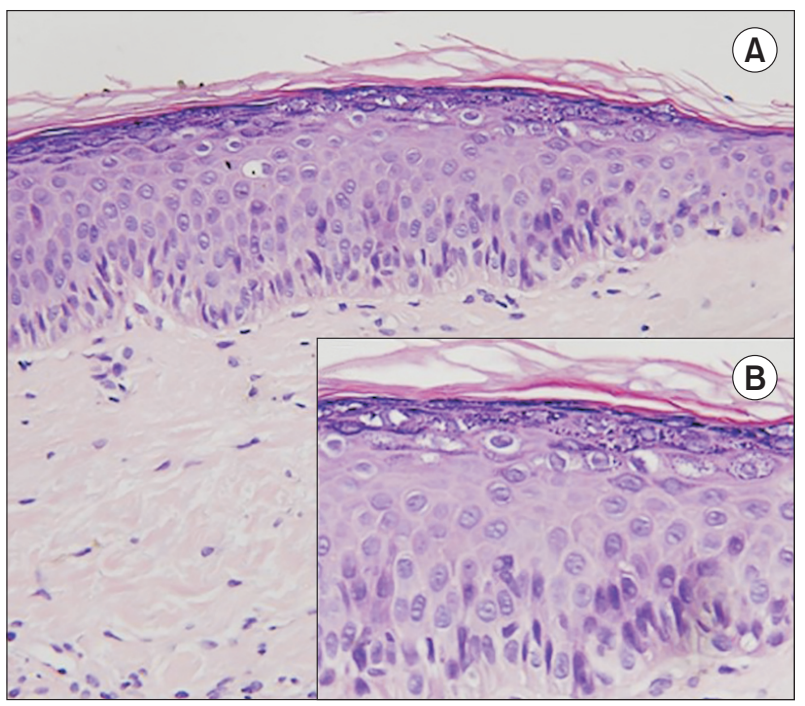

Fig. 1. There is a prominent viral cytopathic effect on the keratinocytes, which includes vacuolization, enlargement, and nuclear basophilia with a prominent granular layer, and a horny layer with a pronounced basket-weave pattern (A: $H \& E, \times 200$; B: H\&E, $\times 400$ ). Cited from from the article of Jung JY, et al. (Ann Dermatol 2009;21:92-4) [31] with original copyright holder's permission. 
Table 2. Skin diseases associated with tattoos and semi-permanent makeup in South Korea

\begin{tabular}{lccc}
\hline \multicolumn{1}{c}{ Etiologic factor } & Clinical diagnosis & Frequency & Year \\
\hline Tattoo pigment & Granulomatous reaction & 1 & $1988[23]$ \\
\hline Henna & Allergic contact dermatitis & 1 & $2005[28]$ \\
\hline Tattoo & Cutaneous pseudolymphoma & 1 & $2007[29]$ \\
Red tattoo & Granulomatous reaction & 1 & $2008[30]$ \\
\hline Semipermanent tattoo & Herpes simplex & 11 & $2008[28]$ \\
Semipermanent tattoo & Contact dermatitis & 9 & $2008[28]$ \\
\hline Semipermanent tattoo & 2ry bacterial infection & 1 & $2008[28]$ \\
Semipermanent tattoo & Facial verruca & 1 & $2009[31]$ \\
Red lip cosmetic tattoo & Granulomatous reaction & 1 & $2014[32]$ \\
\hline Human papilloma virus & Verruca plana & 1 & $2019[33]$ \\
\hline Human papilloma virus & Verruca plana & 1 & $2019[34]$ \\
Semipermanent eye brow tattoo & Granulomatous reaction & 2 \\
Tattoo & Koebner phenomenon at psoriasis & $2020[35]$ \\
\hline
\end{tabular}

with cutaneous pseudo-lymphoma [29]. Complications of the Meibomian gland have also been reported among individuals who received semi-cosmetic eyeliner tattoos. The closer to the opening of the Meibomian gland the procedure happens, the higher the risk of adverse effects [30]. This phenomenon may be explained by the potential damage incurred by the muscle fibers encircling the Meibomian gland or acute inflammatory reactions to tattoo pigments. A 39-year-old female developed multiple verruca plan lesions after undergoing semi-permanent tattooing (Fig. 1) [31]. The types of complications experienced by the recipients of the semi-permanent makeup in South Korea echoed the findings in other foreign countries (Table 2) [23,28-36].

\section{Discussion}

Many who opt for semi-permanent makeup are motivated by esthetics and convenience. A study involving adult female in a single South Korean district observed that an astounding $58.8 \%$ had cosmetic tattoos and only $15.7 \%$ of them were tattooed by medical professionals [36]. Of these, $13.4 \%$ reportedly experienced various side effects from the procedure [37].

As previously stated, tattooing deemed a medical act under Article 19 of the Enforcement Decree of the Public Health Control Act, which stipulates that medical expertise is required for the patient's clinical assessment, treatment, and medical prescription to control disease and avoid complications [38]. Micropigmentation, the medical term for semi-permanent makeup, transfers pigments with extreme precision and accuracy. A biopsy of micropigmented skin confirmed the presence of pigments in the dermal layer, 1-2 mm below the skin's surface
[39]. In contrast, semi-permanent makeup claims to transport pigments from the surface to the granular layer of the epidermis. However, studies including biopsies of the treated skin have yet to confirm that semi-permanent makeup only affects the epidermis and not the dermis. It is questionable whether it is even possible to treat the epidermis and dermis as separate entities during the procedure [25].

The tattoo regulations enforced in foreign countries pertain to practitioner license or qualifications, parlor conditions, hygiene and sanitation, age restrictions, and dyes. For instance, the United States and France allow non-medical personnel to apply semi-permanent makeup in a restricted capacity, while others have entirely prohibited this. Still, most countries that allow non-medical practitioners to practice still require that they have an advanced education in hygiene and infection control or pass an examination before they receive a license [17].

Like Korea, Japan categorizes semi-permanent makeup as a medical practice and bans non-medical personnel from practicing (Article 7, Medical Practitioners' Act). Pursuant to Section 6 of Article 31 of the Medical Practitioners' Act, violators may be punished by imprisonment for a term of up to two years or fined up to 20,000 yen by the Ministry of Health, Labour and Welfare [18].

According to the case law and statutes stated by the National Law Information Center of South Korea, Article 5 of the Act on Special Measures for the Control of Public Health Crimes and Article 25 of the Medical Act permits only medical personnel to practice tattooing [40]. Additionally, Articles 27 and 72 of the Medical Act prohibits practitioners from conducting the practice, no other than medical personnel. If violated, imprisonment of up to five years or a fine of not more than 50 million 
won may be imposed. Furthermore, Article 19 of the Enforcement Decree of the Public Health Control Act states that tattooing is a medical procedure that only a medical practitioner with the capacity to perform clinical examination, prescription, and treatment for disease and infection control may perform.

As the demand for pleasant esthetics and convenience grows, so does the demand for semi-permanent makeup. To meet these needs, it is necessary to expand the number of accredited and respected semi-permanent makeup practices. Some propose that licenses should be issued to non-medical personnel upon completion of an educational course equivalent to that of medical professionals. To that end, the curriculum should include coursework appropriate to the task, hygiene and sterilization standards, facility requirements, procedure regulations, record management skills, and medical indications. Patients in need of a physician involvement include those that seek micropigmentation for medical purposes, have a history of complications associated with tattooing, or request to be treated on sites that exceed certain dimensions [16].

A previous study analyzed various factors involved in the process of making it legal for non-medical personnel to apply semipermanent makeup. Some suggested that requirements should be established for exceptions under which these individuals may practice. Other studies noted the need to modify existing regulations to include informed consent regarding health risks, stricter facility sanitation standards, and the use of verified pigments to eliminate potential threats to both the patient and the public effectively $[10,25]$.

Notably, the practitioner is also highly susceptible to contracting an infection from patients when performing the service. Indeed, bacterial infections such as syphilis, leprosy, Mycobacterium tuberculosis, and atypical Mycobacterium tuberculosis, as well as viral infections such as hepatitis B, hepatitis C, human immunodeficiency virus, human papillomavirus, varicella, and fungal infection have been reported [26,41]. A reporting system, implemented by the Korea Disease Control and Prevention Agency, is designed to detect and prevent the spread of hepatitis $\mathrm{C}$ during illegal procedures performed by non-qualified practitioners [42].

There have been several clinical cases of human papillomavirus infections associated with tattoos, though these may be newly acquired or constitute a relapse of the existing condition [26]. As is the case with most viruses, warts that develop from tattoos have an incubation period of approximately one year, and symptoms begin to appear anywhere from 2 months to 8 years after $[31,34]$. Due to the extensive latency period attribut- ed to the human papilloma virus, it is deemed an infection that requires continuous follow-up.

There is a general lack of awareness regarding potential measures for infection prevention and control. A study in which individuals who underwent semi-permanent makeup procedures were asked about the precautionary steps practitioners took to prevent infection, $53.8 \%$ were uncertain and $27.6 \%$ reported poor hygiene practices. Regarding facility conditions, $57.6 \%$ were neutral, $31.3 \%$ were satisfied, and $11.1 \%$ were dissatisfied [37].

Semi-permanent makeup requires a thorough evaluation of the patient's condition prior to the procedure. If an individual has a history of psoriasis, lichen planus, warts, molluscum contagiosum, herpes simplex [20], or keloids, allergies must be tested before committing to the operation [28]. In addition, it is necessary to check for the use of drugs such as isotretinoin and anticoagulants and advise the patient to discontinue the medication before the operation to avoid potential side effects. It is also crucial to diagnose and treat any allergic reactions that may arise during the operation or herpes simplex, concomitant basal cell carcinoma [16], and malignant melanoma [21]; which may develop postoperatively. Diagnosis, prescriptions, and postprocedural treatment related to semi-permanent makeup are considered medical practices that rely on physicians to ensure patient safety. Hence, it is strongly advised that patients consult a doctor to undergo physical examinations before and after their procedures.

Used needles and gauze are considered among the four types of medical waste. They must be enclosed in a sealed container or bag and disposed of at a medical waste management facility. However, a study revealed that only $44 \%$ of tattoo parlors practice semi-permanent makeup discard this waste separately. Yet, needles, dressing, and gauze used during the tattoo procedure are infectious materials that can potentially spread pathogens [40]. Another study reported that only $33 \%$ of tattoo parlors properly dispose of garbage in the manner appropriate for medical waste [41].

It is difficult for these tattoo parlors to dispose off general medical waste outside of a medical facility. For this reason, many practitioners do not comply with these regulations and often treat this medical waste as general trash. As a result, infection control, which has been overlooked in the past, is becoming a matter of critical public health importance [39].

Since semi-permanent makeup can have a detrimental impact on the health of individuals and the public, it may be necessary to enforce stricter precautionary measures to ensure the 
safety of both patients and the practitioners. Thus, semi-permanent makeup should be categorized as a new medical practice and incorporated into the national health insurance system to promote patient safety. Moreover, the subject should be treated as an entirely separate entity with its own curriculum by medical schools and novel fields in medical science. By acknowledging semi-permanent makeup as a medical practice and reinforcing management and regulation by the relevant ministries, the public can be protected from adverse environmental factors and health effects [37].

There is a pressing need to improve the regulatory safety system to accommodate consumer desires to enjoy semi-permanent makeup without personal and public health concerns. Additionally, education and qualification systems are essential to the process of industrializing semi-permanent makeup and generating highly qualified professionals that can practice on a global level. Hence, Korea should establish a separate qualification system, and the system for training qualified practitioners should be reviewed [12]. Through these measures, practitioners who receive advanced education and training may collaborate with physicians at medical facilities, enabling them to practice safely. Even after a license is issued, additional training and continuous efforts for infectious disease prevention and control are necessary [43].

\section{Conflicts of interest}

The authors have nothing to disclose.

\section{References}

1. Tattoo [Internet]. San Francisco, CA: Wikipedia [cited 2020 Mar 2]. Available from: https://en.wikipedia.org/wiki/Tattoo.

2. Mazza JF Jr, Rager C. Advances in cosmetic micropigmentation. Plast Reconstr Surg 1993;92:750-1.

3. Woo J, Song Y. A study on the awareness, cosmetic behavior, satisfaction and re-treatment of semi-permanent make up. J Korean Soc Cosmetol 2019;25:91-105.

4. Jung YJ. A study on the educational satisfaction of private certificates and the necessity of regular education of semipermanent makeup [dissertation]. Gyeongsan: Daegu Haany University; 2016.

5. Kim SW. Checklist and tattoo contracts to legalize nonmedical personnel tattoos and to ensure the rights of tattoo consumers. KHU Glob Bus Law Rev 2019;12:125-59.

6. Jung YJ, Lee JH. Improvement study for semi-permanent makeup institutionalization. J Invest Cosmetol 2019;15:21528.

7. Long GE, Rickman LS. Infectious complications of tattoos. Clin Infect Dis 1994;18:610-9.

8. Garg G, Thami GP. Micropigmentation: tattooing for medical purposes. Dermatol Surg 2005;31(8 Pt 1):928-31; discussion 931.

9. Traquina AC. Micropigmentation as an adjuvant in cosmetic surgery of the scalp. Dermatol Surg 2001;27:123-8.

10. Kim SY. A study on adult women's cosmetic tattoo experiences and comparison of health concern and health practice between the cosmetic tattooed and non-cosmetic tattooed groups. J Korean Acad Community Health Nurs 2017;28:6977.

11. Kim SM, Yun SK, Kim HU, Ihm CW. Micropigmentation on scalp and eyebrow scars is worth practicing. Korean J Dermatol 2008;46:305-9.

12. Park JS, Ko EB. Kim JH, Kim SK. The base reaearch of safely management of decorative tattoo. Seoul: National Evidencebased Healthcare Collaborating Agency; 2015.

13. Koh HJ, Kim YS. A study on the activity of Korean semipermanent make-up system. Korean J Aesthet Cosmetol 2003;1:1123.

14. Park JS, Kim SK, Kim MJ, Kim SK. Pilot study for understanding the present situation of decorative tattoos. Seoul: National Evidence-based Healthcare Collaborating Agency; 2007. p. 86-101.

15. Kim HH. A study on the actual surver of semi-permanent make-up and improvement plan for the legal system. [dissertation]. Busan: Silla University; 2018.

16. Doumat F, Kaise W, Barbaud A, Schmutz JL. Basal cell carcinoma in a tattoo. Dermatology 2004;208:181-2.

17. Kim CJ. Necessity and policy direction of legalizing tattooist. Seoul: Policy Materials of Parliamentary Inspection of the Administration; 2007.

18. Yang SM, Kim HH. A study on the actual survey of semi-permanent make-up and improvement plan for the legal system. J Korean Soc Cosmetol 2018;24:482-94.

19. Cho SB, Lee SJ, Shim JH, Kim DH. Case analysis of side effects following illegal therapeutic attempts by non-medical personnel. Korean J Dermatol 2008;46:1507-12.

20. Malakar S, Lahiri K. Successful repigmentation of six cases of herpes-labialis-induced lip leucoderma by micropigmentation. Dermatology 2001;203:194.

21. Stinco G, De Francesco V, Frattasio A, Quinkenstein E, Patrone P. Malignant melanoma in a tattoo. Dermatology 2003;206:345- 
6.

22. Khodadost M, Maajani K, Arabsalmani M, Mahdavi N, Tabrizi R, Alavian SM. Is tattooing a risk factor for hepatitis $\mathrm{C}$ transmission?: an updated systematic review and metaanalysis. Hepat Mon 2017;17:e14308.

23. Lee KB, Yi JY, Kim HO, Kim CW. A case of granulomatous reaction to tattoo pigment. Korean J Dermatol 1988;26:554-9.

24. Callaghan MF, Negus C, Leff AP, Creasey M, Burns S, Glensman J, et al. Safety of tattoos in persons undergoing MRI. N Engl J Med 2019;380:495-6.

25. Kim JH. The invasiveness of tattoo and unlicensed medical practice. Korean Criminol Rev 2007;18:165-200.

26. Krecké N, Smola S, Vogt T, Müller CSL. HPV-47-induced and tattoo-associated verrucae planae: report of a case and review of the literature. Dermatol Ther (Heidelb) 2017;7:549-54.

27. Wu CH, Thong HY, Huang CC, Chen PH. Report of two cases of cutaneous Mycobacterium abscessus infection complicating professional decorative tattoo. Dermatol Sin 2017;35:40-3.

28. Cho SB, Lee SJ, Shim JH, Kim DH. Case analysis of side effects following illegal therapeutic attempts by non-medical personnel. Korean J Dermatol 2008;46:1507-12.

29. Shin JB, Seo SH, Kim IH, Son SW. Case analysis of side effects following illegal therapeutic attempts by non-medical personnel. Korean J Dermatol 2007;59:124.

30. Yoon J, Kim AY, Jun RM, Han KE. The effect of eyeliner tattoo on meibomian gland dysfunction and the ocular surface. J Korean Ophthalmol Soc 2020;61:146-52.

31. Jung JY, Shin HS, Won CH, Cho S. Facial verruca plana that developed after semipermanent tattooing. Ann Dermatol 2009;21:92-4.

32. Kwon SH, Choi J, Byun SY, Kim BR, Na JI. A case of foreign body granulomatous reaction to a red lip cosmetic tattoo successfully treated with carbon dioxide laser. Korean J Derma- tol 2014;52:142-3.

33. Park AY, Hong JY, Kim HJ, Chung E, Kim JE, Lee J, et al. A case of tattoo-acquired verruca plana. Korean J Dermatol 2019;57:162-4.

34. Kim SM, Kim JB, Choi HM, Ro BI, Cho HK, Ko EJ. Verruca plana developed after tattooing. Korean J Dermatol 2019;57:1689.

35. Hong E, Lee JD, Cho SH, Woo YR, Kim HS. Two cases of delayed adverse reaction to semi-permanent eyebrow tattoo: review and case report in Korea for granulomatous reaction. Korean J Dermatol 2020;58:334-9.

36. Her Y. Koebner phenomenon following tattooing of a patient with psoriasis. Korean J Dermatol 2020;58:67-8.

37. Kim SH, Shin DH. A study on the current state and the necessity of institutionalization of tattooing for beauty purposes. J Converg Inf Technol 2020;10:201-10.

38. Park JS, Kim SK, Kim MJ, Kim SK. Pilot study for understanding the present situation of decorative tattoos. Seoul: National Evidence-based Healthcare Collaborating Agency; 2015. p. 130.

39. Park KS. Semi-permanent make-up. Seoul: SIDAEGOSI; 2017.

40. Korean Law Information Center. Judicial precedent [Internet]. Sejong: Korea Ministry of Government Legislation; c2019 [cited 2020 Mar 2]. Available from: http://www.law.go.kr/LSW// main.html.

41. Seo EK, Kang SW. Awareness and practice on the prevention of bloodborne infection among semipermanent makeup workers. J Korea Soc Beauty Art 2015;16:147-57.

42. Ministry of Health and Welfare. Hepatitis C prevention and control program. Seoul. Ministry of Health and Welfare. 2016.

43. Kim MY, Youn CS. An exploratory study on the semi-permanent make up legislation. J Beauty Ind 2019;13:81-102. 